\title{
Erratum to: Genetic analysis of intestinal polyp development in Collaborative Cross mice carrying the Apc Min/+ mutation
}

\author{
Alexandra Dorman ${ }^{1}$, Daria Baer ${ }^{1}$, Ian Tomlinson², Richard Mott ${ }^{2}$ and Fuad A. Iraqi ${ }^{{ }^{*}}$
}

\section{Erratum}

Following publication of this article [1], it came to the author's attention that the there was some funding information missing from the acknowledgements section. The updated funding information has been included in the original article and can be seen below:

This study was also supported by a Project Grant from the Israel Cancer Research Fund (ICRF) and a grant from Israeli Science Foundations (ISF) number (961/15).

\section{Author details}

${ }^{1}$ Tel-Aviv University, Tel-Aviv, Israel. ${ }^{2}$ University of Oxford, Oxford, UK.

Received: 9 November 2016 Accepted: 11 November 2016

Published online: 24 November 2016

\section{Reference}

1. Dorman A, Baer D, Tomlinson I, Mott R, Iraqi F. Genetic analysis of intestinal polyp development in Collaborative Cross mice carrying the Apc Min/+ mutation. BMC Genet. 2016;17:1. doi:10.1186/s12863-016-0349-6.

* Correspondence: fuadi@post.tau.ac.il

${ }^{1}$ Tel-Aviv University, Tel-Aviv, Israel

Full list of author information is available at the end of the article 